\title{
Corrosion behaviour of steel rebars embedded in a concrete designed for the construction of an intermediate-level radioactive waste disposal facility
}

\author{
G.S. Duffó ${ }^{1,2,3, a}$, E.A. Arva ${ }^{4}$, F.M. Schulz ${ }^{2,3}$ and D.R. Vazquez ${ }^{1,3}$ \\ ${ }^{1}$ Comisión Nacional de Energía Atómica, Gerencia de Materiales, Departamento Corrosión, División \\ Corrosión Aplicada. Av. Gral. Paz 1499, (1650), San Martín, Buenos Aires, Argentina \\ ${ }^{2}$ Consejo Nacional de Investigaciones Científicas y Técnicas (CONICET). Av. Gral. Paz 1499, \\ (1650) San Martín, Buenos Aires, Argentina \\ ${ }^{3}$ Universidad Nacional de San Martín. Av. Gral. Paz 1499, (1650) San Martín, Buenos Aires, \\ Argentina \\ ${ }^{4}$ Comisión Nacional de Energía Atómica, Programa Nacional de Gestión de Residuos Radioactivos, \\ Av. del Libertador 8250, (1429) Buenos Aires, Argentina
}

\begin{abstract}
The National Atomic Energy Commission of the Argentine Republic is developing a nuclear waste disposal management programme that contemplates the design and construction of a facility for the final disposal of intermediate-level radioactive wastes. The repository is based on the use of multiple, independent and redundant barriers. The major components are made in reinforced concrete so, the durability of these structures is an important aspect for the facility integrity. This work presents an investigation performed on an instrumented reinforced concrete prototype specifically designed for this purpose, to study the behaviour of an intermediate level radioactive waste disposal facility from the rebar corrosion point of view. The information obtained will be used for the final design of the facility in order to guarantee a service life more or equal than the foreseen durability for this type of facilities.
\end{abstract}

\section{Introduction}

Since 1950, the National Atomic Energy Commission (CNEA) of the Argentine Republic works on the development of nuclear energy applications for pacific purposes. The tasks include, among others, the research and development of basic and nuclear technology areas, the operation of important facilities in charge of the production of radioisotopes for medical and industrial applications and the performance of tasks in connection with the nuclear fuel cycle, mining and uranium processing activities, manufacturing of fuel elements, and the operation of two nuclear power plants. As a result of such activities performed in the nuclear field by CNEA and other private and public entities, various types of radioactive waste are being produced. The CNEA is the implementing authority to perform all activities related to the radioactive waste management and sets up the Radioactive Waste Management National Program (PNGRR) [1].

\footnotetext{
a e-mail: duffo@cnea.gov.ar
} 
In order to achieve its objectives the PNGRR is in charge of the adoption of the most appropriate technological solution for the management of such wastes and the scientific-technological support. At the end of the 1990s, the CNEA started an extended research programme which final purpose was to design a facility for the disposal of Intermediate Level Radioactive Waste (ILRW) and to study the long-term behaviour of the materials used for its construction.

ILRW is originated from operation and maintenance activities of the two Argentine Nuclear Power Plants (Atucha I and Embalse), and consist mainly of mechanical filters from the primary circuit of the reactor and by spent ionic exchange resin beds. Such ILRW is under interim storage at the facilities of each power plant awaiting treatment and conditioning, but most of this waste will arise from the decommissioning of the nuclear power plants. Then, the start up of the ILRW repository is linked to the decommissioning of the nuclear power plants and it should be operative approximately by the year 2023 .

In this context, a near-surface monolithic repository based on those in operation in El Cabril, Spain, is foreseen. The conceptual design of this repository is the use of multiple, redundant and independent barriers, and the model considers a 300 years post-closure institutional control [2].

The barriers foreseen for the ILRW repository can be divided into two categories: physical and chemical barriers. The physical barriers are meant to avoid the intrusion of water, people and animals, and the release of radionuclides; while the chemical barriers are intended to restrict radionuclide migration by adsorption and ion-exchange once the soluble radionuclides have been released from the source. The barriers which will be used in the near-surface repository include: waste forms and metallic disposal containers (waste will be immobilized in cement matrices and packed in 200 litre drums or in special concrete containers), backfill and buffer materials, vaults and cover and geological media. The vaults and covers are major components of the engineered barriers, and due to the fact that these barriers are made of reinforced concrete, its durability is an important aspect regarding the integrity of the facility. So, the research and development is focussed on designing a durable concrete and on establishing the methodology to determine its durability, through the knowledge of its performance in the disposal conditions. Of course, durability will be influenced by the environment to which the concrete is exposed to, by the quality of the constituents and their proportion in the mix design and by the structural designs and construction techniques, among other factors. Those uncertainties make the prediction of performance for 300 years impossible to be fully validated. Therefore, as a general criteria, a conservative approach for degradation has to be developed.

This work presents laboratory investigations performed on a prototype built with a formulation candidate to be used in the construction of the ILRW disposal facility, in order to estimate the service life of concrete vaults and cells from the corrosion point of view. Data were obtained with sensors specially designed, in order to monitor the evolution of the rebar state in real conditions. Finally, a comparison between laboratory and field data were done.

\section{Experimental Technique}

An "L shape" reinforced concrete wall (named "prototype") (Figure 1) was built with a high performance concrete developed for this purpose using a pre-welded cage made with $10 \mathrm{~mm}$ diameter rebars. The chemical composition of the reinforcing bars used in the study is as follows: $\mathrm{C}$, $0.41 \%$; Mn, 0.73\%; Cu, 0.27\%; Ni, 0.13\%; Si, 0.28\%; P, <0.01\%; S, 0.02\%; N, 0.008\%; Fe, balance. The concrete used in this study was selected based, among other characteristics, on the mechanical properties and workability. The composition of the concrete used, as well as some of its properties are summarized in Table 1. 


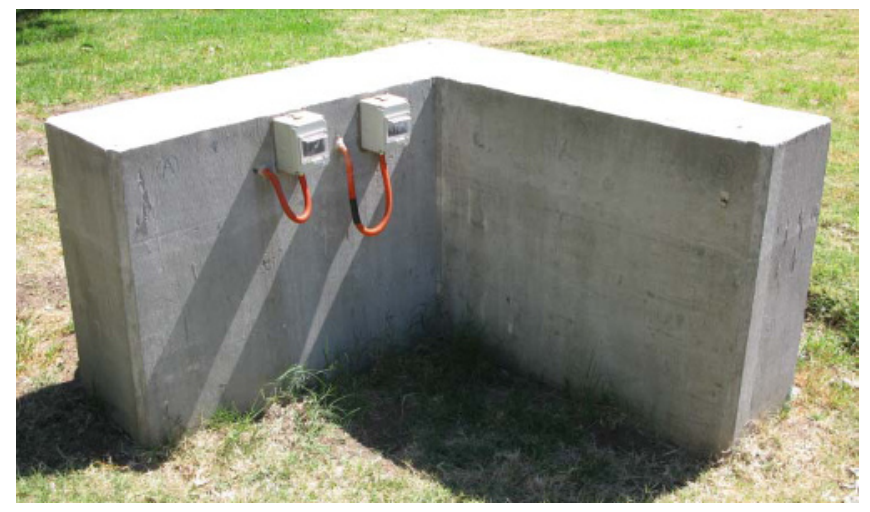

Fig. 1. Instrumented concrete wall simulating the corner of a cell showing the electrical contacts of the embedded sensor.

Table 1. Composition and mechanical properties of the concrete used in the present work..

\begin{tabular}{|l|c|}
\hline Water $\left(\mathrm{kg} / \mathrm{m}^{3}\right)$ & 154.1 \\
\hline $\begin{array}{l}\text { Cement CAH40 }(\mathrm{SR}) \\
\text { IRAM } 50000\left(\mathrm{~kg} / \mathrm{m}^{3}\right)\end{array}$ & 416.4 \\
\hline Sand $\left(\mathrm{kg} / \mathrm{m}^{3}\right)$ & 813.4 \\
\hline Coarse Aggregate $\left(\mathrm{kg} / \mathrm{m}^{3}\right)$ & 995.2 \\
\hline Additives $\left(\mathrm{kg} / \mathrm{m}^{3}\right)$ & 2.94 \\
\hline w/c & 0.37 \\
\hline $\begin{array}{l}\text { Compressive strength } \\
(\text { MPa }) 28 \text { days }\end{array}$ & $52.1 \pm 1.0$ \\
\hline Capillary suction $\left(\mathrm{g} / \mathrm{cm}^{2}\right)$ & 886 \\
\hline Air Permeability $\left(\mathrm{m}^{2}\right)$ & $0.018 \times 10^{-16}$ \\
\hline
\end{tabular}

The cover concrete of this prototype is $50 \mathrm{~mm}$. This wall simulates the corner of the radioactive waste disposal cells, and was built in the Centro Atómico Constituyentes grounds, of the National Atomic Energy Commission, where the external temperature was measured periodically. Three corrosion sensors, specially developed in the laboratory [3], were embedded in the prototype in order to monitor the evolution of several parameters associated with the corrosion process along time: the temperature inside the structure, the corrosion potential and the corrosion rate of the reinforcing bars, the electrical resistivity of concrete and the availability of oxygen. The measurements started 28 days after the concrete was discharged into formwork. This monitoring has been followed for approximately 1700 days (about 4.7 years), and it will continue for the next years.

Besides, the carbonation rate of the concrete was determined after 7.2 years exposure using cylindrical concrete specimens $(10 \mathrm{~cm}$ diameter and $10 \mathrm{~cm}$ height $)$ by the phenolphthalein test.

\section{Results and discussion}

Figure 2 shows the evolution of the temperature measured inside the prototype as a function of time. The figure also includes the evolution of the average external temperature measured in the same place where the prototype is installed. It can be seen that the internal temperature is always higher that the external one, being the difference higher during the summer periods, when the difference reaches almost $15^{\circ} \mathrm{C}$. 


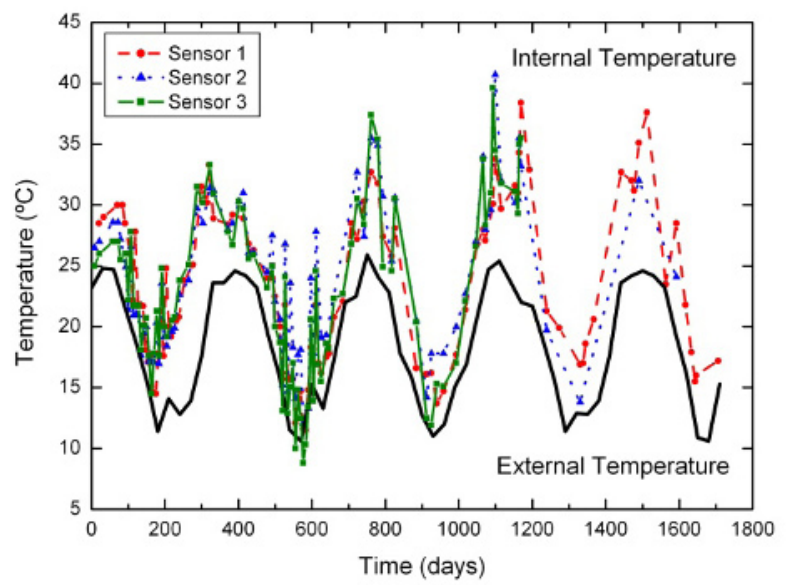

Fig. 2. Evolution of the internal temperature of the prototype and the average external temperature as a function of time.

Figure 3 shows the evolution of the concrete electrical resistivity as a function of time. The evolution of the internal temperature is also included (in all the following cases, for the sake of simplicity, only the values provided by one of the sensors are included). It should be noted that the progression of the hydration is well reflected by the increase in electrical resistivity. The impact of the cycle of temperature along the year on the electrical resistivity is remarkable: the higher the temperature, the lower the electrical resistivity. The same might happen with the other parameters measured so, care has to be taken when interpreting on-site results.

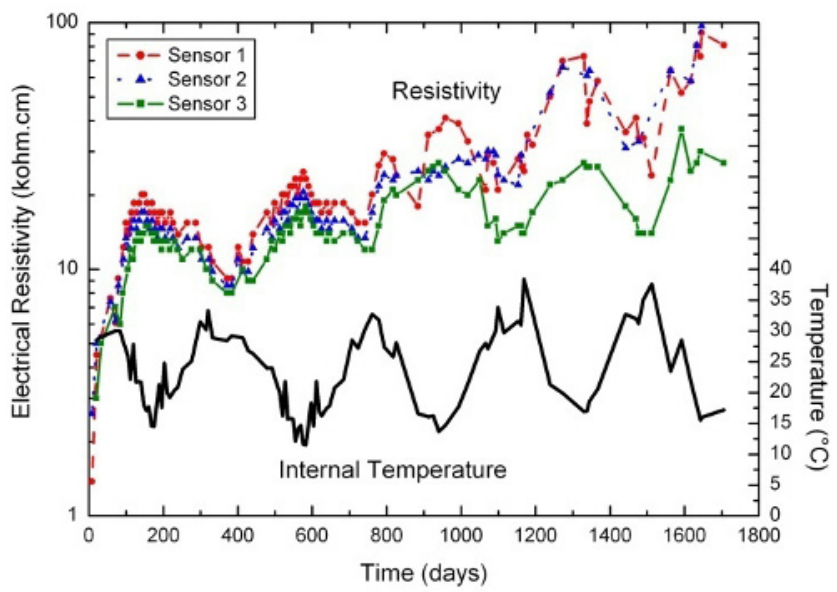

Fig. 3. Evolution of the electrical resistivity of the prototype and its internal temperature as a function of time.

Figure 4 shows the evolution of the corrosion potential of the reinforcing bars as a function of time. It can be seen that the corrosion potential is almost constant along the 3 year measurement period, with a small tendency to increase. In all cases, the value are close to $-0.2 \mathrm{~V}_{\mathrm{SCE}}$ that, according to ASTM C-876 [4] standard, is the borderline between intermediate and low corrosion risk.

Figure 5 shows the evolution of the oxygen flow as a function of time. A progressive decrease of the oxygen flow, reaching the rebars, can be observed without this being noticed by changes in the corrosion potential values. The trend of the oxygen flow follows the trend of the internal 
temperature: the higher the internal temperature, the higher the oxygen flow. Again, the impact of the cycle of temperature along the year on the measured parameter is noticeable.

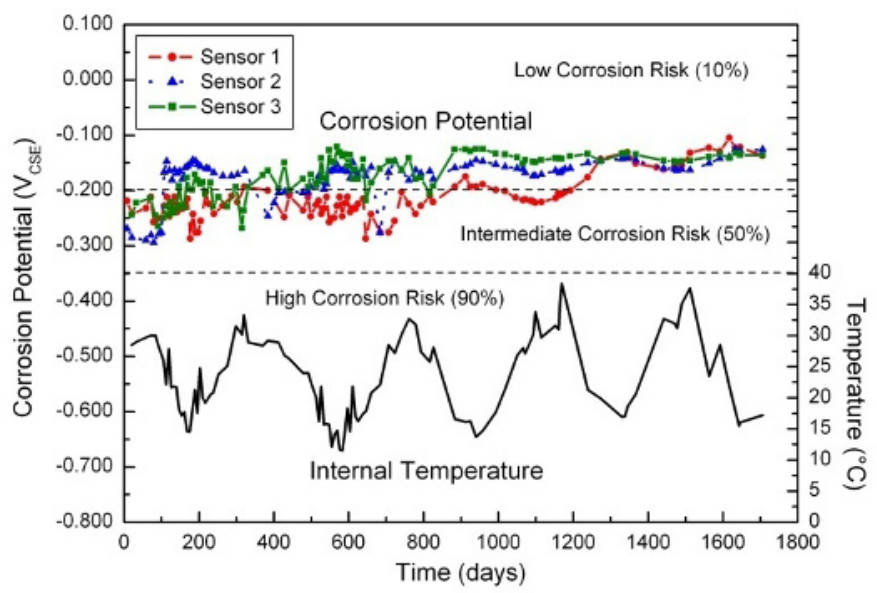

Fig. 4. Evolution of the rebar corrosion potential of the prototype and its internal temperature as a function of time.

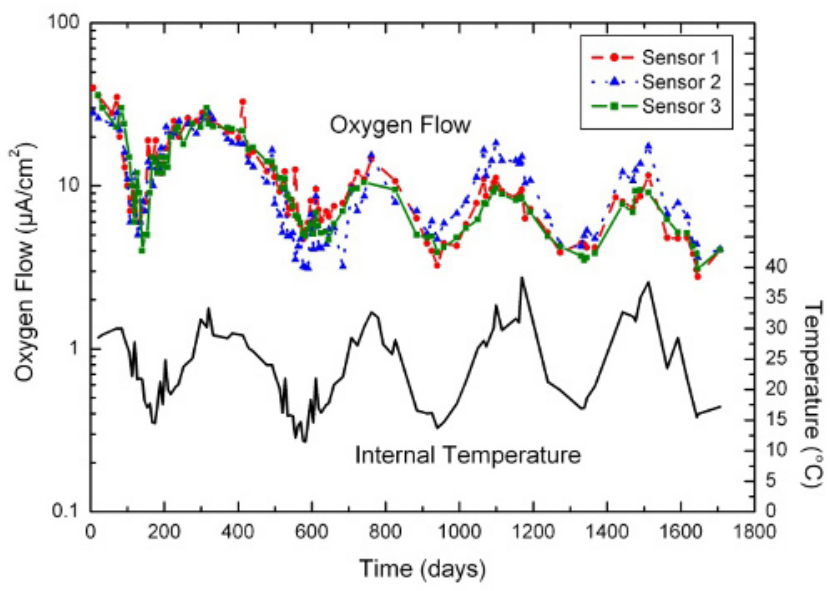

Fig. 5. Evolution of the oxygen flow of the prototype and its internal temperature as a function of time.

Figure 6 shows the evolution of the corrosion rate of the rebars (data obtained with the embedded sensors) as a function of time. The corrosion rate starts from $30 \mu \mathrm{m} /$ year and, after 3 years, it reaches a value close to $2 \mu \mathrm{m} /$ year. From this figure it is possible to deduce that the temperature evolution due to the seasonal changes is, again, the most influencing factor for the trends recorded. The reinforcement corrosion rate values are in the borderline between low and negligible corrosion rate [5].

The carbonation depth after 7.2 years exposure was $6.9 \mathrm{~mm}$. These values give a carbonation rate $(\mathrm{k}$ in the equation $\mathrm{x}=\mathrm{k} \cdot \mathrm{t}^{0.5}$, $\mathrm{x}$ being the carbonation depth and $\mathrm{t}$ the exposure time), of 2.59 mm.years ${ }^{-0.5}$. The values of the carbonation rate obtained in the present work compared with those obtained by Andrade et al. [6] for the same type of application show that, up to the moment, the values obtained in the present case are higher than those measured in the "El Cabril" facility (Figure 7). 


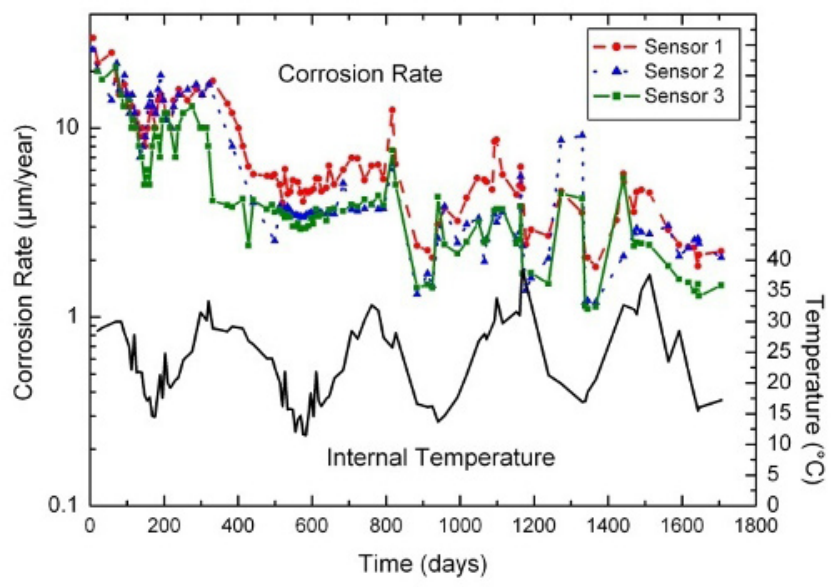

Fig. 6. Evolution of the corrosion rate of the prototype and its internal temperature as a function of time.

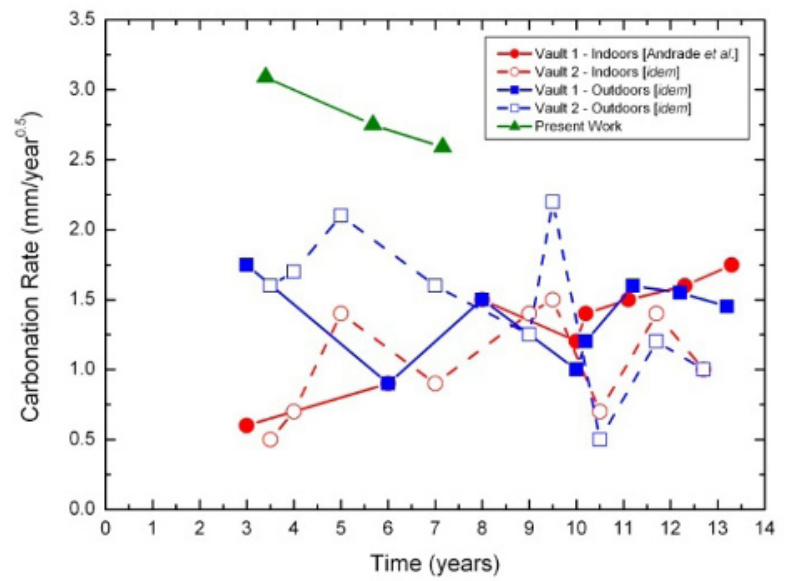

Fig. 7. Evolution with time of the carbonation rate calculated in the present work, compared with values obtained with control specimens in El Cabril [6].

The comparison of the corrosion potential and corrosion rate data obtained in laboratory [7] and those obtained in the prototype seems to be not straightforward: the prototype shows lower corrosion potentials and higher corrosion rates than those obtained in laboratory specimens. The explanation for this phenomenon is that rebars embedded in the laboratory specimens were free of rusting, while the pre-welded cage of the prototype, after being exposed to the atmosphere for several days without any protection, underwent atmospheric corrosion and the steel were covered by a red type of corrosion product. These products were not properly eliminated before the cast of the concrete. It is a known fact that clean steel electrodes behave differently than pre-corroded ones. Mortar alkalinity by itself, or that provided by $\mathrm{Ca}(\mathrm{OH})_{2}$ saturated solutions, which rapidly passivates a clean steel surface, does not ensure passivation of pre-rusted steel. In fact, rebars with pre-rusted surfaces exhibit unacceptable corrosion rates, even in non-carbonated concrete with a very low concentration of chloride [8-11]. The same results have been reported even in stainless steels, in which cheaper low-alloyed steels with bare surfaces are more resistant than expensive high-alloyed scaled steels [12]. One of the causes of this non-expected corrosion rate on pre-rusted surfaces might be the contamination of the rust layer during atmospheric exposure prior to the steel's embedding in concrete. However, the major cause might be the rust layer itself that acts as a barrier for alkaline 
solution from the concrete to reach the rebars. This fact is very interesting as in the actual construction practice pre-rusted steel bars are generally used.

Based on the Tuuti's service life model [13], no propagation period must be considered for ILRW disposal facilities because, according to the service criterion proposed by Andrade and Alonso [14], it is assumed that the durability of these structures ends once rebar corrosion has been initiated. In order to fulfil this criterion, the concrete must be designed to completely avoid corrosion during the period of almost 300 years. However, it should be mentioned that the effect of a passive state over 300 years deserves further study because, it is not known if a passive corrosion rate occurring during a very long time could lead to the formation of an oxide layer able to generate mechanical stresses in the concrete cover [15]. If corrosion (propagation period) is likely to occur during the ILRW disposal service life, the theoretical safety is very much reduced and a high risk of loosing the barrier properties exists before accomplishing the expected life. Two consequences of this statement are: ILRW facilities must not be located in places where chlorides, sulphates or the carbonation front could reach the rebar during the service life of the structure. In addition, all other degradation processes, which might affect cover integrity and impermeability (leaching, sulphate attack, freezing and thawing, etc), have to be avoided as part of the design phase.

The location selected for the construction of the ILRW disposal facility should be compatible with long-term concrete performance. That is to say, the site should be at a considerable distance from chloride containing environments (e.g. marine environments) and located in an area with no abnormal content of carbon dioxide and other acid contaminants. Then, the most important cause of reinforced corrosion is the carbonation during the period in which the vaults are kept in contact with air [6]. Knowing the diffusion rate of $\mathrm{CO}_{2}$ in the concrete studied, after 300 years, the carbonation depth will be about $45 \mathrm{~mm}$ (assuming a constant value of the carbonation rate equal to that obtained after 7.2 years exposure, although the experimental results show that the carbonation rate decreases with time). The design of the containers and cells foresee a concrete cover of $50 \mathrm{~mm}$, that is to say, the concrete under study will fulfil the requirements for the expected life-time.

In conclusion, if the concrete is properly designed and carefully produced with good quality control forms, it is as an inherently durable material. However, several factors may affect the durability of concrete: constituent materials, construction practices, physical properties, environmental exposure conditions and types of loads. One of the most important factors is connected to the construction practices, i.e. to avoid the use of pre-rusted rebars. It is well recognized that concrete construction methods and practices influence the final quality of the concrete. Besides, the placement of concrete, that includes transporting the concrete to the jobsite delivery point, discharging into formwork, consolidating and providing proper curing conditions, will ensure adequate durability, serviceability and structural integrity in accordance to design specifications. It is worth to mention that, up to now, the site for the Argentine near-surface disposal facility has not been determined. So, as soon as this location is established, it will be necessary to fully characterize the environment for the correct identification of key parameters involved in the long term durability.

\section{Conclusions}

- The concrete studied in the present work showed that the value of the carbonation rate is adequate to comply with the foreseen specifications.

- The corrosion rate as well as other parameters related to rebars durability measured in a prototype, shows values that are not in accordance with those obtained in laboratory specimens. This is due to the use of pre-rusted reinforced bars that increases the corrosion susceptibility of rebars. Besides, the impact of the cycle of temperature along the year on the parameter measured is remarkable so, this effect should be carefully taken into account when applying durability models. 
- In order to fully evaluate the behaviour of reinforced concretes, once the selection of the site for the near surface disposal facility is made, the medium and long term evolution of the parameters under study should be followed up.

\section{Acknowledgments}

The financial support of the CONICET (Consejo Nacional de Investigaciones Científicas y Técnicas); the FONCYT, Agencia Nacional de Promoción Científica y Tecnológica, Argentina, and the Universidad Nacional de San Martín is acknowledged.

\section{References}

1. Joint convention on the safety of spent fuel management and on the safety of radioactive waste management.http://www.cab.cnea.gov.ar/residuos/CC2003/0002-SecA.pdf (march/25/2011)

2. F.M. Schultz, E.A. Arva, G.S. Duffo, Studies concerning the reinforcement corrosion of concrete vaults for intermediate-level radioactive waste disposal, in: V. L'Hostis, R. Gens, C. Gallé (Eds.), Long Term Performance of Cementitious Barriers and Reinforced Concrete in Nuclear Power Plants and Waste Management (RILEM Publications SARL, Paris, 2009)

3. G.S. Duffó, S.B. Farina, Constr. Build. Mater. 23, 2746 (2009)

4. ASTM C 876, Standard test method for half-cell potential for uncoated reinforcing steel in concrete (American Society of Testing and Materials, Philadelphia, 1987)

5. M.C. Andrade, M. C. Alonso, Constr. Build. Mater. 15, 141(2001)

6. C. Andrade, I. Martínez, M. Castellote, P, Zuloaga, J. Nucl. Mater. 358, 82 (2006)

7. G.S. Duffó, E.A. Arva, F.M. Schulz and D.R. Vazquez, J. Nucl. Mater. 420, 382 (2011)

8. J.A. Gonzalez, E. Ramirez, A. Bautista, S. Feliu, Cem. Concr. Res. 26, 501 (1996)

9. $\quad$ P.Novak, R. Mala, L. Josta, Cem. Concr. Res. 31, 589 (2001)

10. T.U. Mohammed, H. Hamada, Cem. Concr. Res. 33, 1103 (2003)

11. J.A. González, J.M. Miranda, E. Otero, S. Feliu, Corros. Sci. 49, 436 (2007)

12. M. Kouřil, P. Novák, M. Bojko, Cem. Concr. Res. 40, 431 (2010)

13. K. Tuutti, Corrosion of steel in concrete (Swedish Cement and Concrete Institute, Stockholm, 1982)

14. Andrade, C. and Alonso, M.C., Values of corrosion rate of steel in concrete to predict service life of concrete structures, in: G. Cragnolino, N. Sridhar (Eds.), Application of accelerated corrosion tests to service life prediction of materials, ASTM-STP 1194 (ASTM International, Philadelphia, 1994)

15. V. L’Hostis, F. Foct, P. Dillmann, J. Nucl. Mater. 379, 124 (2008) 